\title{
Weldability of Fe-Al-Cr Overlay Coatings for Corrosion Protection in Oxidizing/Sulfidizing Environments
}

\author{
March 1, 2003 \\ Research Sponsored by the U.S. Department of Energy, \\ Office of Fossil Energy \\ Advanced Research Materials Program \\ Report Prepared by \\ J.R. Regina, J.N. DuPont, and A.R. Marder \\ Lehigh University \\ Energy Research Center \\ 117 ATLSS Drive \\ Bethlehem, PA 18015-4729 \\ under \\ 19X-SU604V \\ for \\ OAK RIDGE NATIONAL LABORATORY \\ Oak Ridge, Tennessee 37831 \\ Managed by \\ UT-BATTELLE, LLC \\ for the \\ U.S. DEPARTMENT OF ENERGY \\ under contract DE-AC05-00OR22725
}




\subsection{EXECUTIVE SUMMARY}

The effect of chromium additions to the weldability of Fe-Al based overlay claddings are currently being investigated for the corrosion protection of boiler tubes in Low NOx furnaces. The primary objective of this research is to identify weldable (crack-free) FeAl-Cr weld overlay coating compositions that provide corrosion resistance over long exposure times. During the current project phase, preliminary corrosion testing was conducted on several ternary Fe-Al-Cr alloys in two types of gaseous corrosion environments. These long-term corrosion tests were used to develop a target weld composition matrix and serve as a base line for future corrosion tests. Preliminary Fe-Al based welds with various aluminum concentrations and one ternary $\mathrm{Fe}-\mathrm{Al}-\mathrm{Cr}$ weld overlay were successfully deposited using a Gas Tungsten Arc Welding (GTAW) process and cracking susceptibility was evaluated on these coatings.

Research sponsored by the U.S. Department of Energy, Fossil Energy Advanced Research Materials Program, DOE/FE AA 151010 0, Work Breakdown Structure Element $L U-2$. 


\subsection{INTRODUCTION}

Iron-aluminum based alloys have been considered as coatings for the protection of waterwall boiler tubes found in coal-fired furnaces. These iron-aluminum based alloys are potentially good candidates for boiler tube coatings because they have excellent corrosion resistance to a wide range of high temperature gaseous environments including highly sulfidizing environments ${ }^{1-5}$. These coatings are advantageous over commercial alloys such as stainless steels and Ni-based superalloys, because they are significantly less expensive than the commercial alloys, they do not experience microsegregation as seen in the Ni-based superalloys, and they do not form a brittle interface at the fusion zone as seen in some stainless steel weld overlays ${ }^{6,7}$.

Studies have shown that increasing the aluminum content of Fe-Al based alloys increases the corrosion resistance of the alloy in high temperature environments containing oxygen and sulfur ${ }^{2,4,5}$. It has been reported that aluminum contents need to be approximately $10 \%$ (all values are in wt $\%$ ) in order for binary $\mathrm{Fe}-\mathrm{Al}$ alloys to demonstrate protective corrosion behavior in oxygen and sulfur bearing atmospheres at $500^{\circ} \mathrm{C}^{8,9}$. Chromium additions up to $5 \%$ have also been shown to improve the corrosion behavior of $\mathrm{Fe}-\mathrm{Al}$ based alloys in high temperature oxidizing and sulfidizing environments ${ }^{9}$. In the previous project phase it was reported that at operating temperatures of $500^{\circ} \mathrm{C}, \mathrm{Fe}-\mathrm{Al}-\mathrm{Cr}$ alloys require around $10 \% \mathrm{Al}$ and chromium additions up to $5 \%$ to be completely protective in simulated low NOx atmospheres for 100 hours of exposure (Figure 1$)^{9}$.

Unfortunately, Fe-Al welds are sensitive to hydrogen induced cracking (cold cracking) at certain weld compositions. Weldablility studies have shown that the cold cracking phenomenon seen in $\mathrm{Fe}-\mathrm{Al}$ weld overlays is directly related to the aluminum content of the weld overlay regardless of the welding parameters ${ }^{4,7}$. It has been determined that for binary Fe-Al weld overlay claddings, welding compositions below approximately $10 \% \mathrm{Al}$ can be deposited crack-free, while welds with compositions above $10 \% \mathrm{Al}$ are susceptible to hydrogen cracking (Figure 2). Although the corrosion behavior of Fe-Al weld overlays would improve by increasing the aluminum content in the coatings, a compositional limit for welding is approximately $10 \% \mathrm{Al}$. 
It can be seen from the $\mathrm{Fe}-\mathrm{Al}$ phase diagram in Figure 3 that the ordered intermetallics, $\mathrm{Fe}_{3} \mathrm{Al}$ and $\mathrm{FeAl}$, are present at lower temperatures at approximately 11$35 \% \mathrm{Al}$. These two intermetallic alloys have been reported to experience low room temperature ductility due to their sensitivity to environmental embrittlement ${ }^{10-13}$. Environmental embrittlement in these alloys has been attributed to the release of free hydrogen from a reaction between aluminum and water vapor that can be written as ${ }^{14}$ :

$$
2 \mathrm{Al}+3 \mathrm{H}_{2} \mathrm{O} \rightarrow \mathrm{Al}_{2} \mathrm{O}_{3}+6 \mathrm{H}^{+}+6 \mathrm{e}^{-}
$$

Studies have therefore shown that $\mathrm{Fe}_{3} \mathrm{Al}$ and $\mathrm{FeAl}$ are not inherently brittle at room temperature, but can experience acceptable room temperature ductility values when tested in environments containing no water vapor ${ }^{10,11}$. For comparison, it should be noted that disordered alloys $(\alpha)$ tested in wet air have been reported to have room temperature ductility values of approximately $25 \%$, compared to $\mathrm{Fe}_{3} \mathrm{Al}$ ductility values of $2-4 \%^{11,15}$. The compositional boundary between the ordered intermetallic $\mathrm{Fe}_{3} \mathrm{Al}$ and the disordered iron solid solution $(\alpha)$ lies at approximately $10-11 \% \mathrm{Al}$, which may account for the lack of weldability at higher aluminum contents. It should also be mentioned that the addition of chromium to $\mathrm{Fe}_{3} \mathrm{Al}$ has helped improve the room temperature ductility of alloys tested in air containing moisture ${ }^{16,17}$.

The primary objectives of this study are: (1) to investigate the effect of chromium on the weldability of Fe-Al based weld overlays and to determine $\mathrm{Fe}-\mathrm{Al}-\mathrm{Cr}$ weld overlay compositions that are not susceptible to hydrogen cracking; (2) to determine the effect of chromium on $\alpha / \mathrm{Fe}_{3} \mathrm{Al}$ compositional boundary and find if the presence of $\mathrm{Fe}_{3} \mathrm{Al}$ has a role in the susceptibility to hydrogen cracking; and (3) to evaluate the corrosion performance of weldable Fe-Al-Cr weld overlays at long exposure times. 


\subsection{EXPERIMENTAL PROCEDURE}

\section{Weldability Study}

Preliminary weld overlay coatings were deposited using a mechanical Gas Tungsten Arc Welding (GTAW) system with a computer controlled table and cold wire feeders (Figure 4). Binary Fe-Al welds were produced by depositing aluminum filler metal wire (1100) onto plain carbon steel substrates (A285C). Fe-Al-Cr weld overlay claddings were made by simultaneously depositing two filler metal wires: aluminum (1100) and ferritic stainless steel (430), onto plain carbon steel substrates (A285C). The filler metal wire and substrate compositions can be seen in Table 1. Two filler metal wires were used to produce $\mathrm{Fe}-\mathrm{Al}-\mathrm{Cr}$ welds in order to have independent control over the aluminum and chromium contents of the welds and allow for systematic variations of the two primary alloying elements. During this phase of the project, welds will be made with aluminum contents ranging 5-15\% $\mathrm{Al}$ and chromium levels of approximately 0-10\%. Although these are target weld compositions, aluminum and chromium contents will be increased until cracking occurs in order to determine the maximum alloying content that can be achieved in a crack-free weld.

The welding current and the filler metal feed rates were adjusted to vary the weld overlay compositions. Once welds were deposited, they were allowed to cool for 24 hours before being inspected for cracking. Macroscopic observations were made on the weld overlays to search for cracking before a dye penetration technique was used to count the number of cracks. The dye penetration was done by cleaning the weld surface, spraying the dye penetrant onto the weld, and allowing the dye to soak into the metal. After approximately five minutes, the dye was wiped from the surface and a developer was sprayed on the weld to bring out the cracks, which can be seen in Figure 5. Light Optical Microscopy (LOM) will also be used during the study to investigate any microcracks that may be present in the welds. Once the weld deposits were examined for cracking, the fusion zone was removed from the substrate and wet chemical analysis was performed on the weld to determine the aluminum and chromium contents of the deposits. 


\section{Order-Disorder Transformation}

Once Fe-Al-Cr weld overlays have been deposited and examined for cracking, welds with compositions along the crack/no crack boundary will be selected for analysis in the Transmission Electron Microscope (TEM). The TEM will be used to determine if the ordered intermetallic $\mathrm{Fe}_{3} \mathrm{Al}$ is present in welds that experienced cracking. Ordered phases can be identified using the TEM due to the presence of anti-phase boundaries (APB) in ordered structures. APB's are boundaries within an ordered structure where the atomic periodicity or order is interrupted. Ordered phases cannot be identified using light optical or scanning electron microscopy, but APB's can be seen using dark field imaging techniques on the TEM (Figure 6). Therefore, samples will be removed from welds adjacent to cracks and from the weld matrix using a Focused Ion Beam (FIB). TEM analysis will consist of diffraction and dark field imaging to identify the phases that are present in crack-free welds as well as cracked welds.

\section{Long-Term Corrosion Testing}

Corrosion testing will be performed on cast $\mathrm{Fe}-\mathrm{Al}-\mathrm{Cr}$ alloys with compositions similar to compositions of selected crack-free weld overlay deposits. Samples will be exposed to an oxidizing environment and a mixed oxidizing/sulfidizing environment at $500^{\circ} \mathrm{C}$ for exposure times of $100,500,1000$, and 2000 hours. The compositions of the two corrosive gaseous environments can be seen in Table 2. Water vapor present in the corrosive environments will be injected into the gas stream at a controlled rate via a capillary tube and a syringe pump. The samples will be weighed to the nearest tenth of a milligram using a digital balance before and after exposure. The total weight change over the exposure times will be reported and scale morphology observations will be made using Scanning Electron Microscopy (SEM) and Energy Dispersive Spectroscopy (EDS). Reported preliminary corrosion samples were analyzed using an accelerating voltage of $5 \mathrm{keV}$ and EDS analysis was carried out at $15 \mathrm{keV}$. 


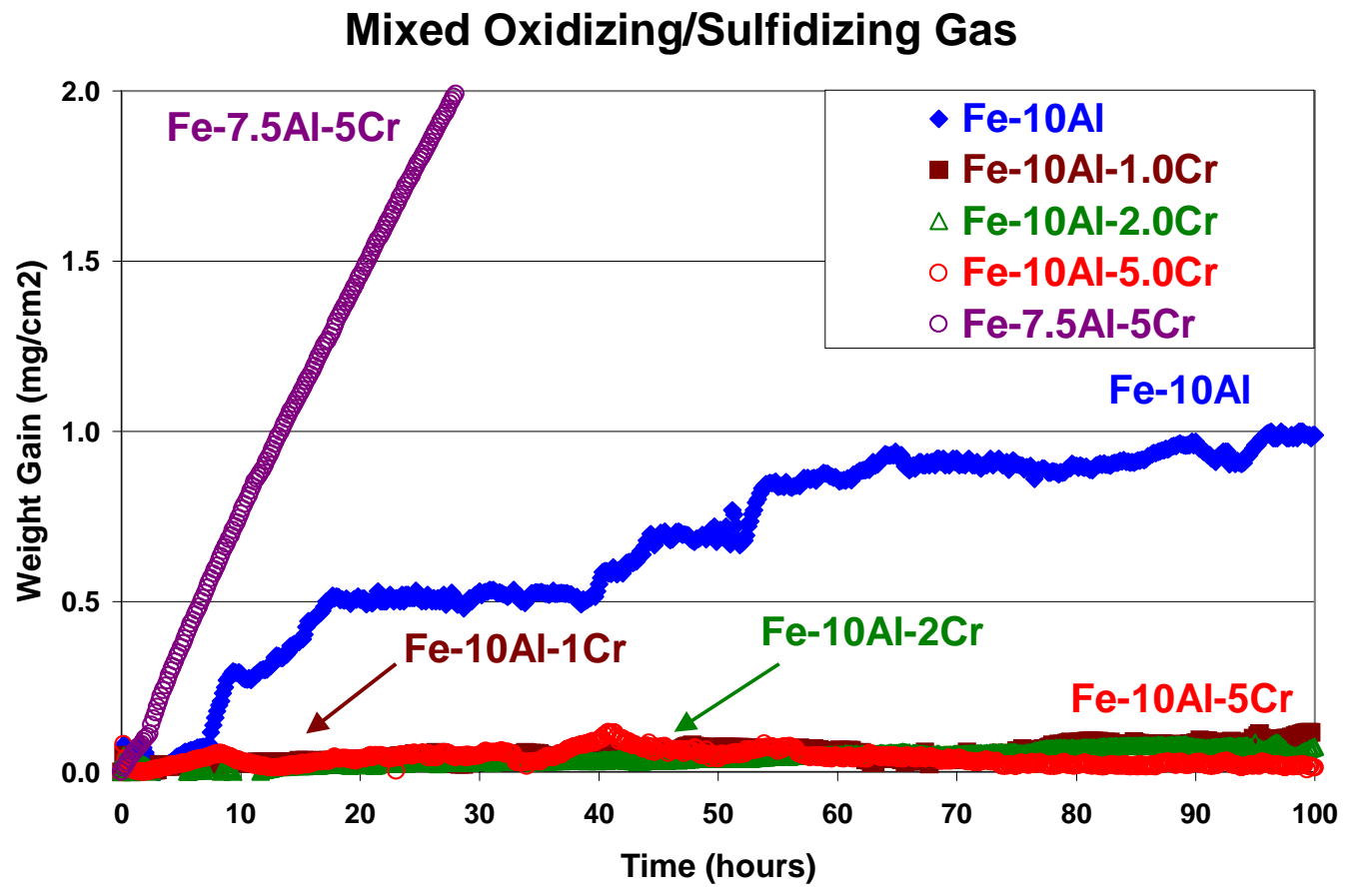

(a)

Oxidizing Environment

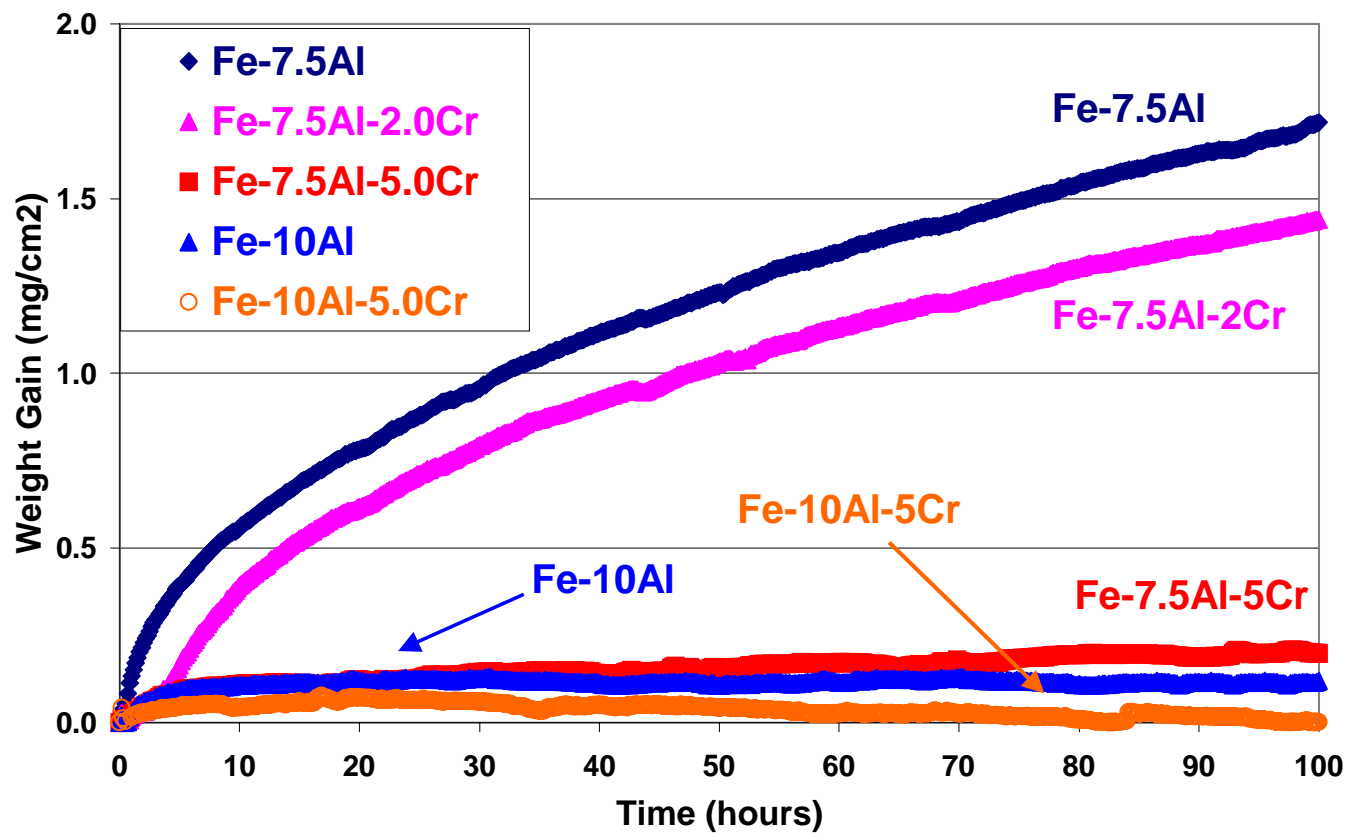

(b)

Figure 1 - Corrosion behavior of Fe-Al-Cr alloys exposed to (a) the mixed oxidizing/sulfidizing atmosphere and (b) to the oxidizing environment at $500^{\circ} \mathrm{C}$. 


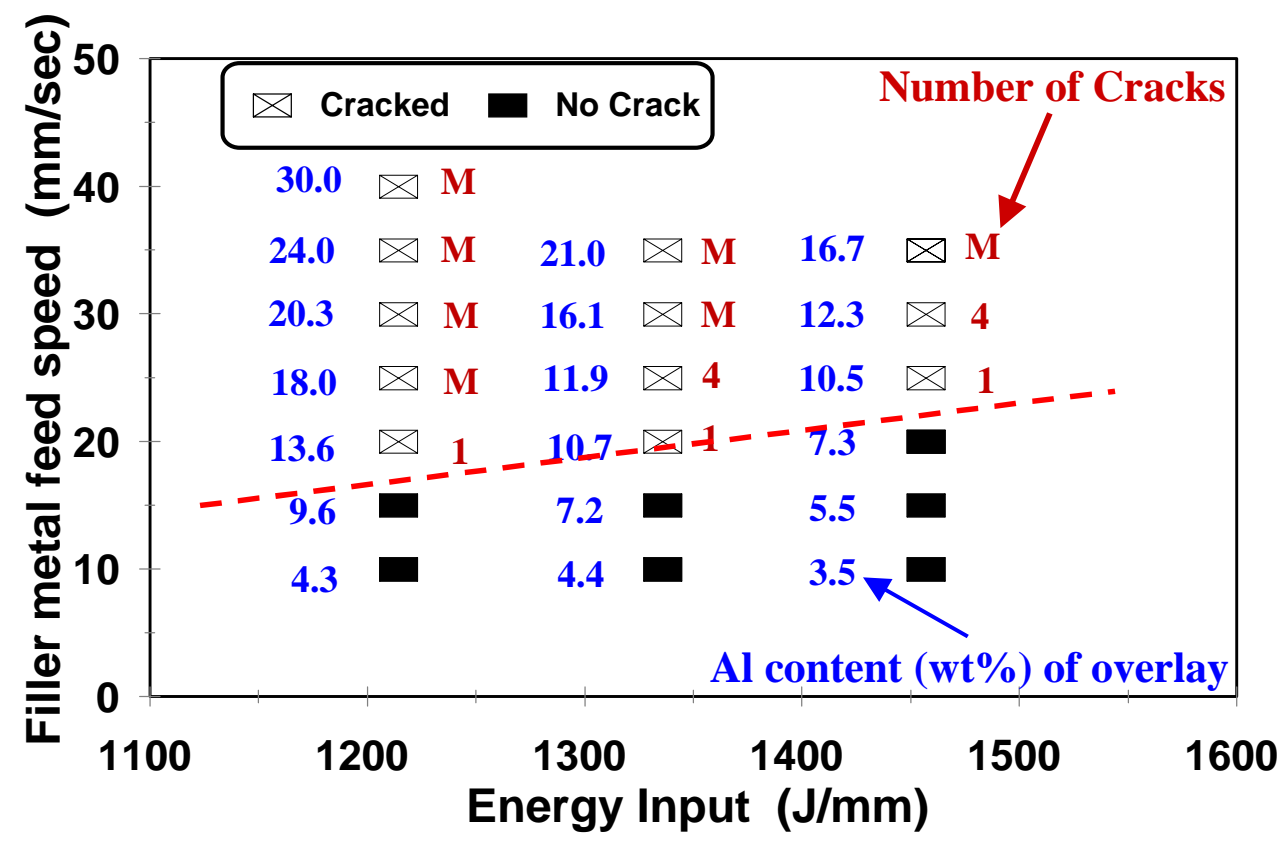

Figure 2 - Fe-Al weld overlay cracking susceptibility on coatings produced by GTAW. Each box represents a deposited weld and is labeled as cracked or no crack. The number on the left of each box is the aluminum content of the weld and the number to the right of each point is the number of cracks observed, where $\mathrm{M}$ represents more than 15 cracks $^{7}$.

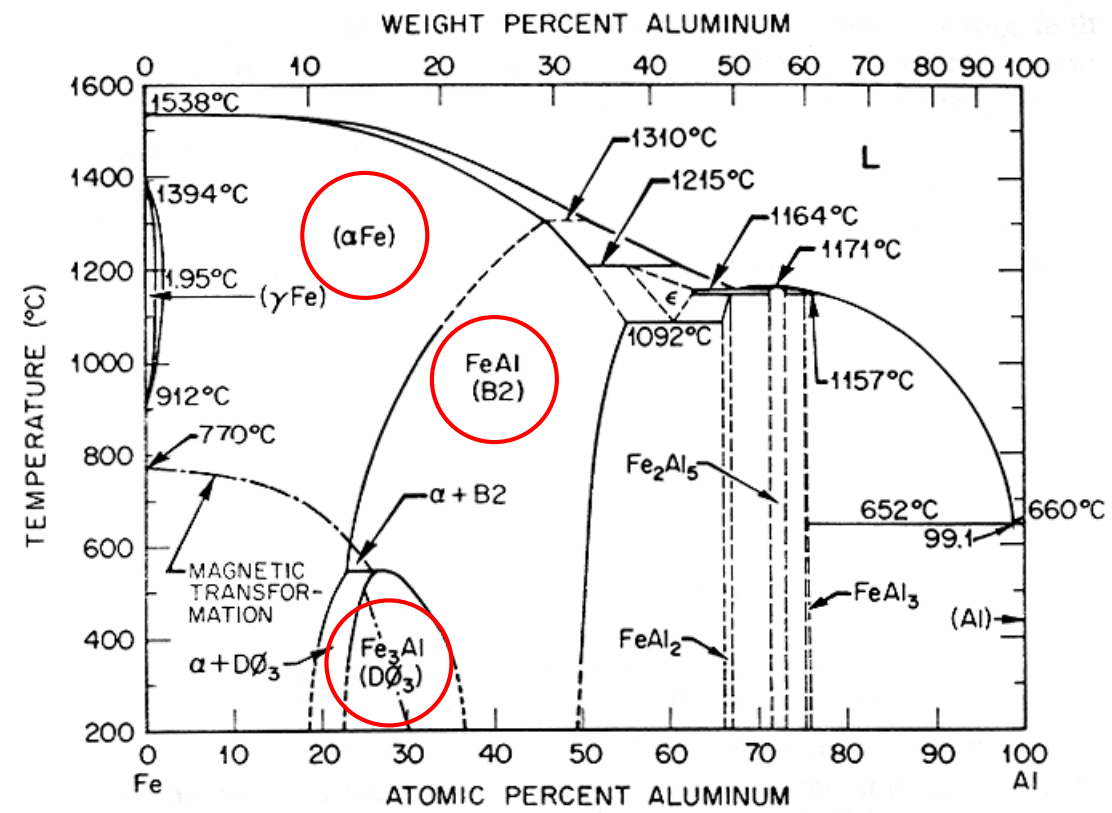

Figure 3 - Fe-Al equilibrium phase diagram showing the disordered iron solid solution $(\alpha)$ and the ordered intermetallic phases $\left(\mathrm{Fe}_{3} \mathrm{Al}\right.$ and $\left.\mathrm{FeAl}\right)$ that are present from approximately $11-35 \mathrm{wt} \% \mathrm{Al}$. 


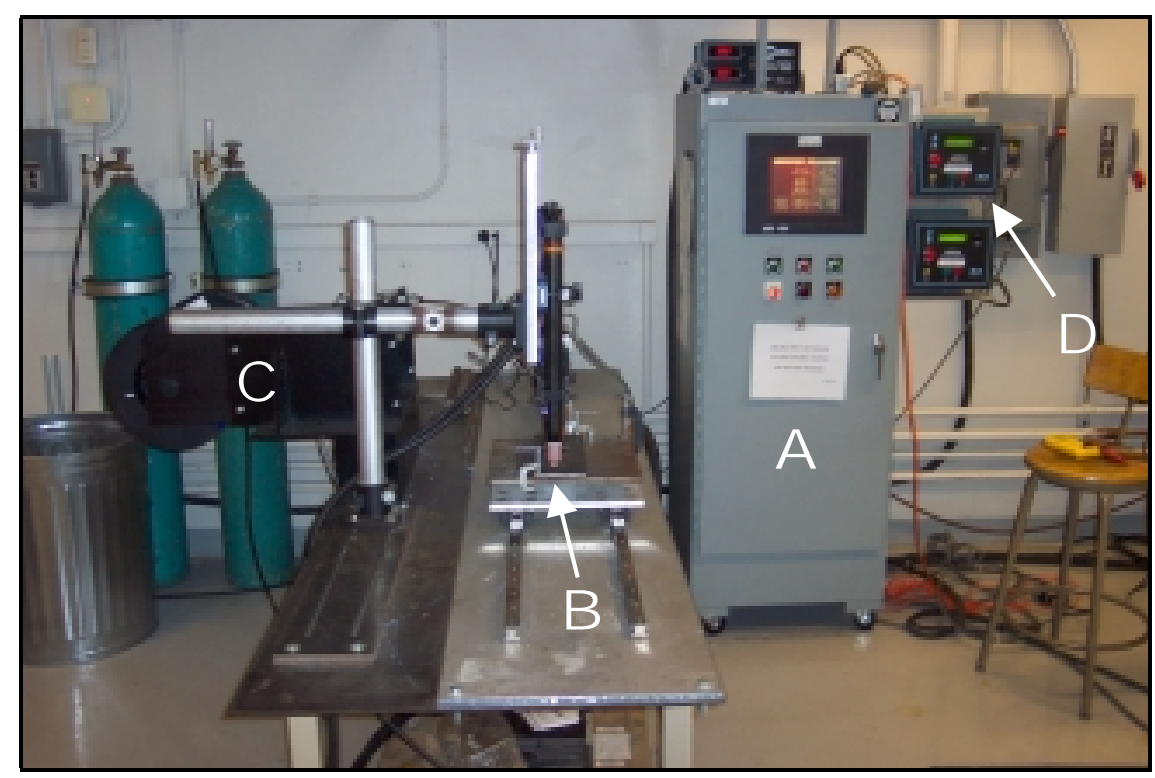

(a)

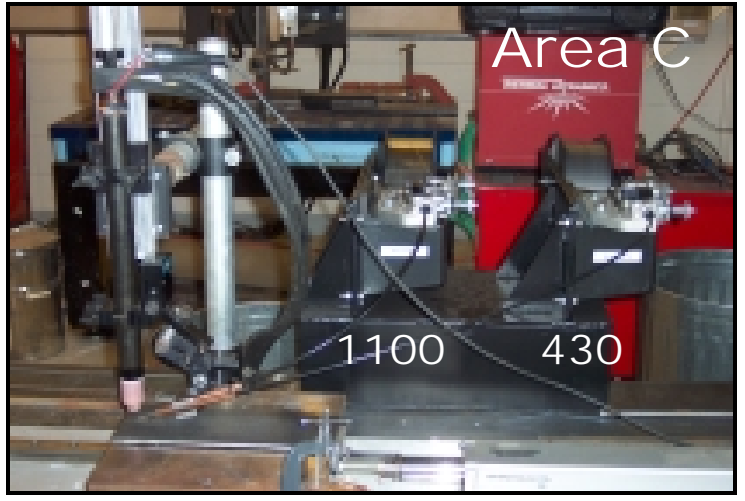

(b)

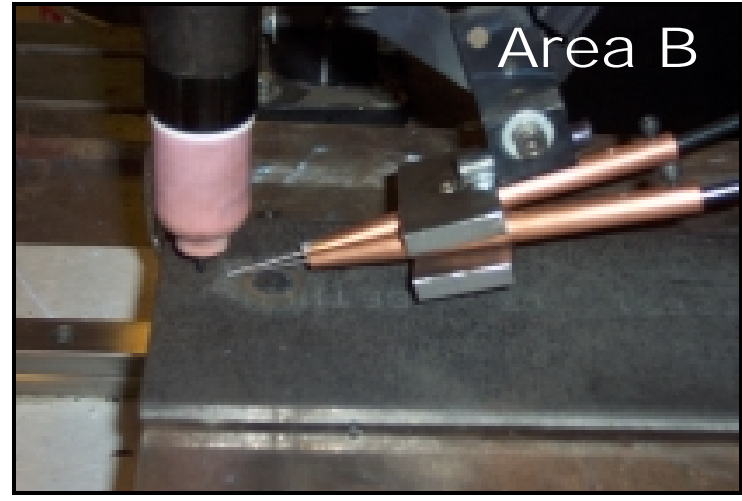

(c)

Figure 4 - GTAW welding setup (a) showing the table and torch control panel (A), the actual table and GTAW torch (B), the two cold wire feeders (C), and the cold wire feeder control units (D). Cold wire feeder setup (b) showing the two filler metal wires (1100 and 430) and a close up of the torch tip (c) showing the two-wire setup. 


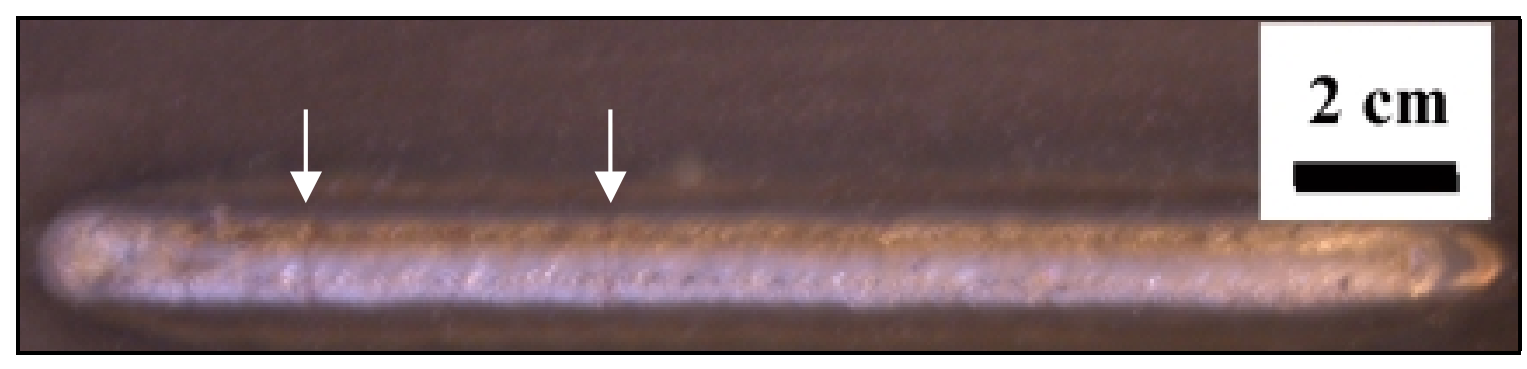

(a)

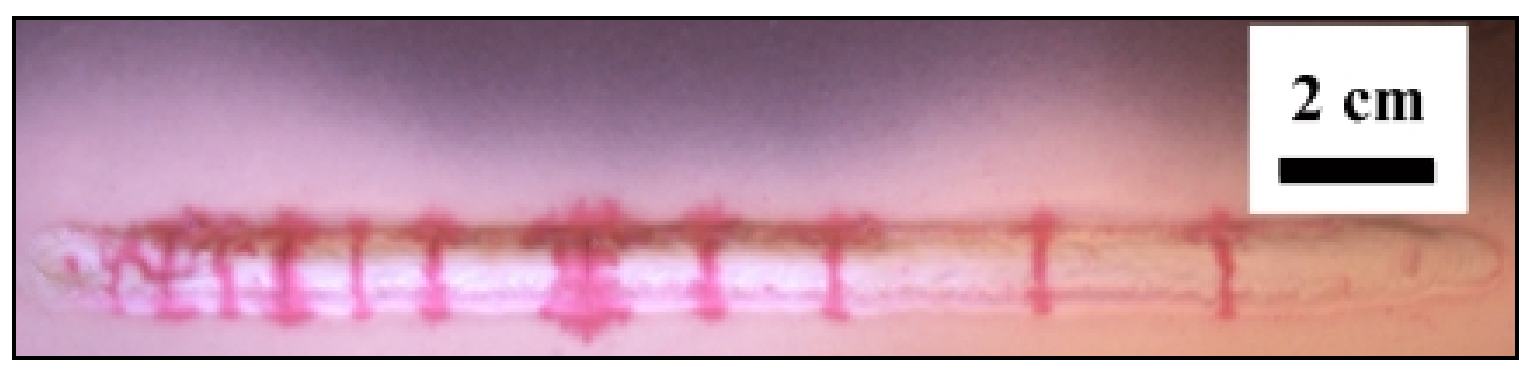

(b)

Figure 5 - Binary Fe-Al weld overlay cladding shown without any dye penetrant (a) showing that some cracks were observable without the dye (arrows) and the same weld with the dye (b) showing many more cracks (red).

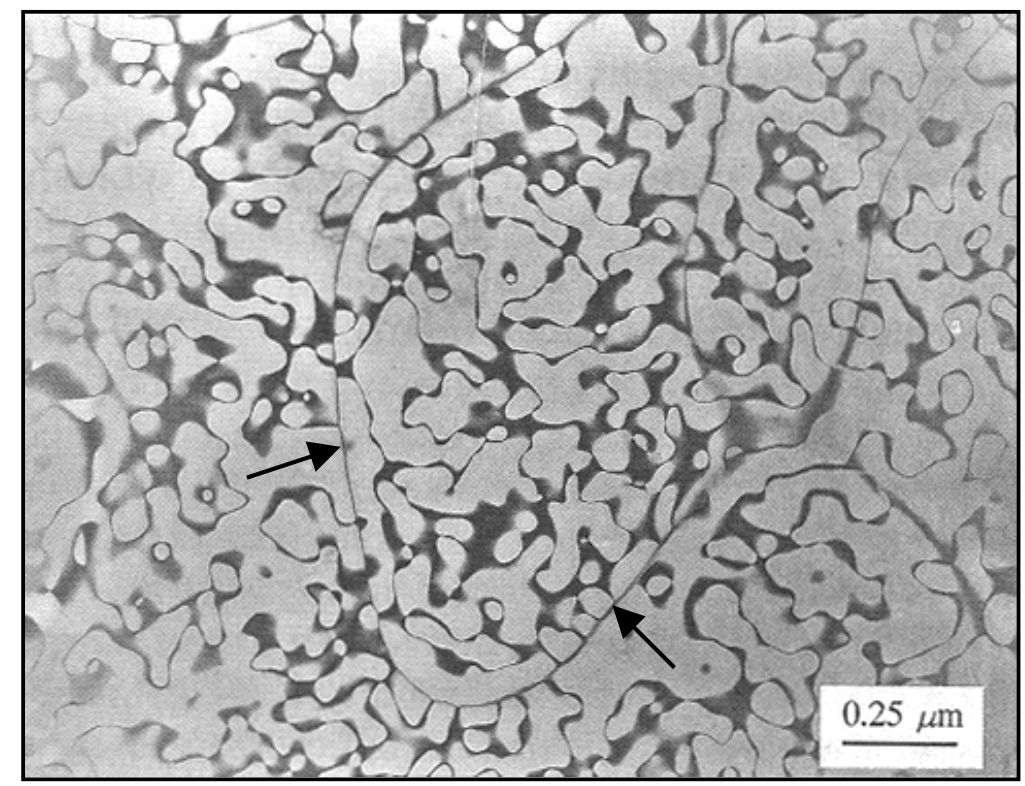

Figure 6 - Dark field TEM image showing APB's in $\mathrm{Fe}_{3} \mathrm{Al}$ (small rounded boundaries). Due to the formation of $\mathrm{FeAl}$ prior to the formation of $\mathrm{Fe}_{3} \mathrm{Al}$ during cooling, FeAl APB's can be seen as well (arrows). 
Table 1 - Alloy compositions for the two filler metal wires and the substrates (wt $\%$ ).

\begin{tabular}{|c|c|c|c|c|c|c|c|c|}
\hline & $\mathbf{C}$ & $\mathbf{M n}$ & $\mathbf{S i}$ & $\mathbf{C r}$ & $\mathbf{P}$ & $\mathbf{S}$ & Al & Other \\
\hline \hline $\begin{array}{c}\text { Aluminum } \\
\text { Wire (1100) }\end{array}$ & ----- & ------ & ----- & ----- & ----- & ----- & 99.0 & $0.12 \mathrm{Cu}$ \\
\hline $\begin{array}{c}\text { Stainless Steel } \\
\text { Wire (430) }\end{array}$ & 0.10 & 1.0 & 1.0 & $\begin{array}{c}16.0- \\
18.0\end{array}$ & 0.06 & 0.03 & ------ & ------ \\
\hline $\begin{array}{c}\text { Steel Substrate } \\
(\text { A285C) }\end{array}$ & 0.28 & 0.9 & ----- & ----- & 0.035 & 0.040 & ----- & ----- \\
\hline
\end{tabular}

Table 2 - Gas compositions used for corrosion testing (vol. \%).

\begin{tabular}{|c|c|c|}
\hline Gas Component & Mixed Oxidizing/Sulfidizing Gas & Oxidizing Gas \\
\hline \hline $\mathbf{O}_{2}$ & ------- & 2 \\
\hline $\mathbf{C O}$ & 10 & -------- \\
\hline $\mathbf{C O}_{2}$ & 5 & 15 \\
\hline $\mathbf{H}_{2}$ & -------- & 6 \\
\hline $\mathbf{H}_{\mathbf{2}} \mathbf{O}$ & 2 & -------- \\
\hline $\mathbf{H}_{2} \mathbf{S}$ & 0.12 & 0.12 \\
\hline $\mathbf{S O}_{2}$ & -------- & Bal. \\
\hline $\mathbf{N}_{2}$ & Bal. & -2 \\
\hline $\mathbf{L o g} \mathbf{P o}_{2}$ & -19 & -46 \\
\hline Log Ps & -8 & \\
\hline
\end{tabular}

\subsection{RESULTS AND DISCUSSION}

\section{Weldability Study}

Six binary Fe-Al weld overlay coatings and one ternary Fe-Al-Cr weld overlay were deposited using the GTAW setup described above. The welding parameters that were used to deposit the preliminary weld overlays can be seen in Table 3. Weld overlay compositions obtained by wet chemical analysis and the number of reported cracks can be seen in the table as well. From this table it can be seen that adjusting the welding current and the filler metal feed rates resulted in weld overlay claddings with various aluminum and chromium contents. The cracking behavior of the preliminary Fe-Al 
welds can be directly compared to previously reported results by plotting the energy input and filler metal feed speed welding parameters as shown in Figure 7. From this figure it can be seen that even at higher energy input values and filler metal feed speeds, the cracking behavior of the binary Fe-Al weld overlays is a function of weld composition only. These preliminary results on the binary Fe-Al weld overlay claddings show that the previous results are reproducible and that the binary compositional welding boundary is at approximately $10 \% \mathrm{Al}$.

The ternary Fe-Al-Cr weld overlay deposit (Weld G) was deposited crack-free and contained aluminum and chromium contents of $8.9 \%$ and $7.2 \%$, respectively. Light optical microscopy (LOM) revealed that the fusion zone of the weld was comprised of a columnar grain structure and appeared to be continuous throughout the fusion zone (Figure 8). It was also noted that there was no distinct boundary in the fusion zone that may be present if there is not sufficient mixing between the two filler metal wires. If there is not sufficient mixing within the weld pool during deposition, one wire may be deposited on top of the other wire. The lack of a distinct boundary implies that good mixing occurred in the weld pool during deposition. Although it appears as though the weld deposited with both filler metal wires mixed sufficiently enough to result in a homogeneous fusion zone, Electron Microprobe Analysis (EPMA) must be performed on the weld overlay to ensure that the composition is homogeneous and that there are no mixing issues during welding.

\section{Long-Term Corrosion Testing}

Three Fe-Al-Cr alloys were tested at $500^{\circ} \mathrm{C}$ for 100 and 500 hours in the oxidizing and mixed oxidizing/sulfidizing environments listed in Table 2. The three alloys tested were $\mathrm{Fe}-10 \mathrm{Al}, \mathrm{Fe}-10 \mathrm{Al}-2 \mathrm{Cr}$, and $\mathrm{Fe}-10 \mathrm{Al}-5 \mathrm{Cr}$ (all values are in wt\%) and the alloys were selected based on results from the previous project phase, which reported that Fe-10Al$2 \mathrm{Cr}$ and $\mathrm{Fe}-10 \mathrm{Al}-5 \mathrm{Cr}$ were the two alloys that preformed best during 100 hours exposures. It can be seen in Figure 9 that the Fe-10Al sample resulted in a weight gain during the 100 and 500 hour exposures to the oxidizing gas and Fe-10Al-2Cr showed a small weight gain value during the 500 hour exposure. On the other hand, $\mathrm{Fe}-10 \mathrm{Al}-5 \mathrm{Cr}$ demonstrated no significant weight gains up to 500 hours of exposure to the oxidizing 
gas. Analysis of the scale morphology of the Fe-10Al alloy revealed that the corrosion product that formed was comprised of two types of scales: sphere-like nodules that formed on areas of bare metal, and a plate-like scale that grew out of the sphere-like nodules (Figure 10). Both of the corrosion scales were identified as iron oxide compounds by EDS, which was consistent with results obtained from the previous project phase that reported two scale morphologies on samples exposed to the oxidizing environment.

Figure 11 shows the corrosion results for alloys exposed to the mixed oxidizing/sulfidizing environment for 100 and 500 hours. Note that the weight gain axis on this figure is much larger than that on Figure 9. It was seen that Fe-10Al demonstrated a significant weight gain during both the 100 and the 500 hour exposures. Both the Fe-10Al-2Cr and Fe-10Al-5Cr alloys resulted in no weight gain up to 500 hours of exposure. The scale morphology observed on the Fe-10Al sample exposed to the mixed oxidizing/sulfidizing gas can be seen in Figure 12. A thick block-like corrosion scale that cracked and spalled easily was observed to completely cover the sample and was identified as an iron sulfide compound from EDS. These results were consistent with results from the previous project phase that reported that block-like iron sulfide scales formed on samples exposed to the mixed oxidizing/sulfidizing gas. The corrosion results for $\mathrm{Fe}-10 \mathrm{Al}-5 \mathrm{Cr}$ are promising, but longer exposure times are required to completely characterize the long-term corrosion behavior of these alloys. 
Table 3 - Welding parameters used for each weld overlay deposit, the resulting weld composition, and the number of cracks detected for each weld ( $\mathrm{N}$ represents no cracking).

\begin{tabular}{|c|c|c|c|c|c|c|}
\hline Weld & $\begin{array}{c}\text { Weld } \\
\text { Current } \\
(\mathbf{a m p s})\end{array}$ & $\begin{array}{c}\text { Measured } \\
\text { Voltage } \\
(\mathbf{V})\end{array}$ & $\begin{array}{c}\text { Al Wire } \\
\text { Feed Rate } \\
(\mathbf{m m} / \mathbf{s})\end{array}$ & $\begin{array}{c}\text { FeCr } \\
\text { Wire } \\
\text { Feed Rate } \\
(\mathbf{m m} / \mathbf{s})\end{array}$ & $\begin{array}{c}\text { Weld } \\
\text { Composition } \\
(\mathbf{w t} \%)\end{array}$ & $\begin{array}{c}\text { Number } \\
\text { of } \\
\text { Cracks }\end{array}$ \\
\hline $\mathbf{A}$ & 250 & 11.1 & 41.5 & 0.0 & $\mathbf{1 8 . 1 \%} \mathrm{Al}$ & $\mathbf{4}$ \\
\hline $\mathbf{B}$ & 250 & 11.0 & 58.0 & 0.0 & $\mathbf{2 7 . 1 \%} \mathrm{Al}$ & $\mathbf{1 2}$ \\
\hline $\mathbf{C}$ & 250 & 10.5 & 17.0 & 0.0 & $\mathbf{6 . 4 \%} \mathrm{Al}$ & $\mathbf{N}$ \\
\hline $\mathbf{D}$ & 275 & 11.0 & 33.0 & 0.0 & $\mathbf{1 1 . 9 \%} \mathbf{A l}$ & $\mathbf{1}$ \\
\hline $\mathbf{E}$ & 275 & 11.3 & 41.5 & 0.0 & $\mathbf{1 2 . 4 \%} \mathbf{A l}$ & $\mathbf{4}$ \\
\hline $\mathbf{F}$ & 300 & 12.1 & 25.0 & 0.0 & $\mathbf{5 . 4 \%} \mathbf{A l}$ & $\mathbf{N}$ \\
\hline \hline $\mathbf{G}$ & 250 & 11.3 & 25.0 & 60.0 & $\mathbf{8 . 9 \%} \mathrm{Al-7.2 \%} \mathbf{C r}$ & $\mathbf{N}$ \\
\hline
\end{tabular}

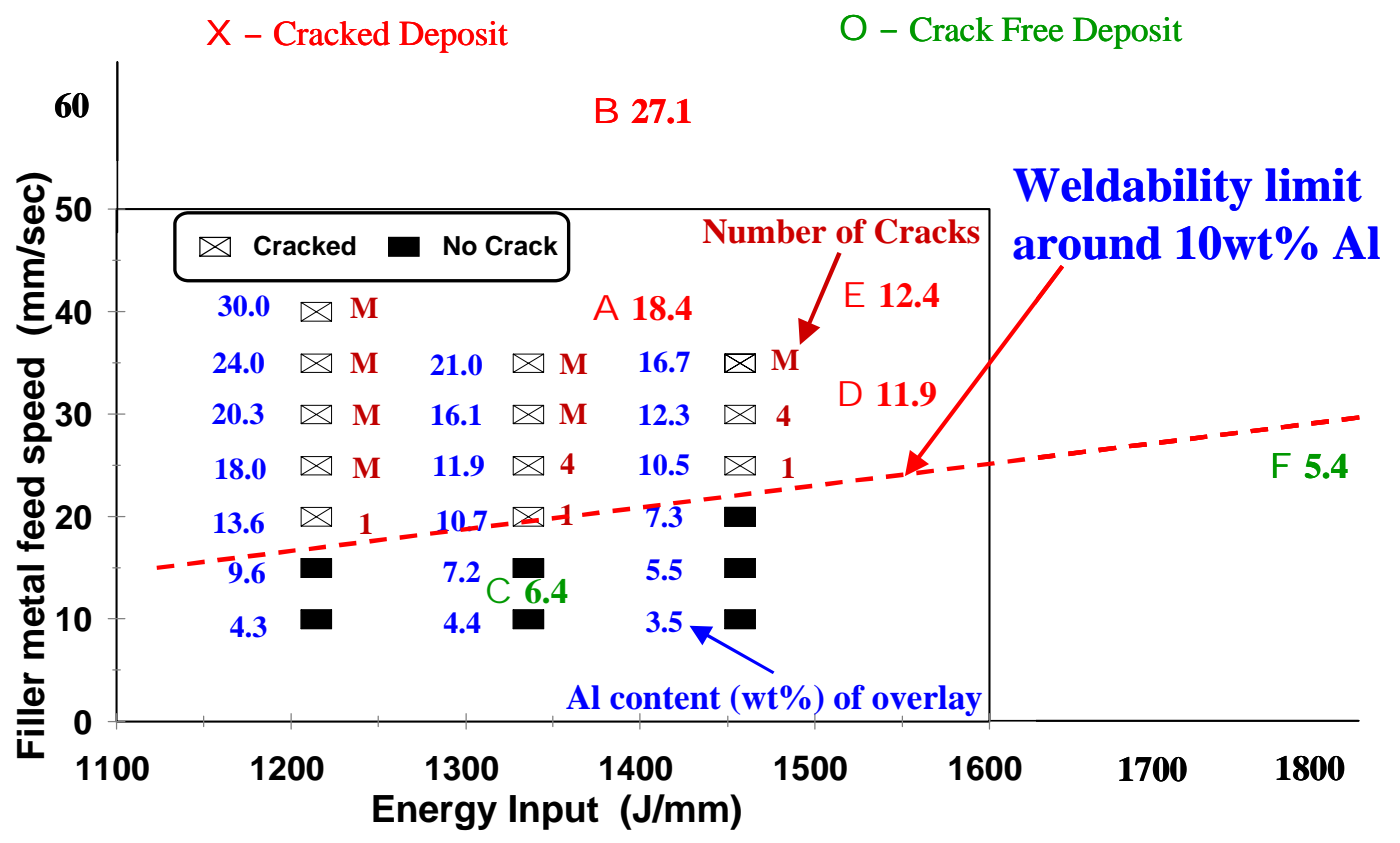

Figure 7 - Preliminary weld overlay deposits plotted onto weldability curve shown in Figure 2. Each letter corresponds to the weld deposit and the number to the right of the letter indicates the weld aluminum content. Red letters represent welds that cracked and green letters were used for welds that were not susceptible to hydrogen cracking. 


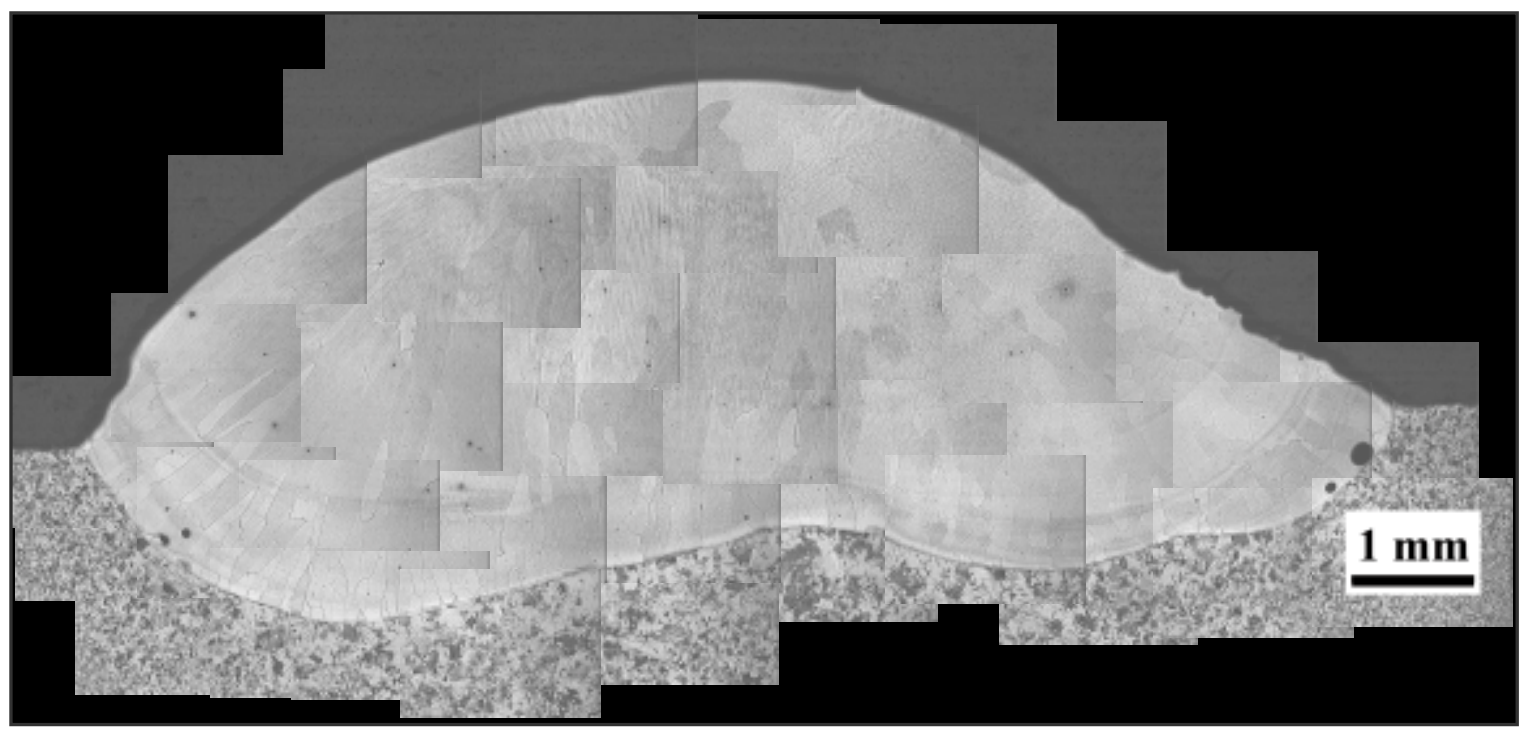

Figure 8 - Light optical montage of the cross-sectioned Fe-Al-Cr weld overlay deposit (Weld G). It can be seen that a columnar grain structure was present in the fusion zone and that there was no distinct boundary within the fusion zone, implying that good mixing occurred in the weld pool.

\section{Oxidizing Environment}

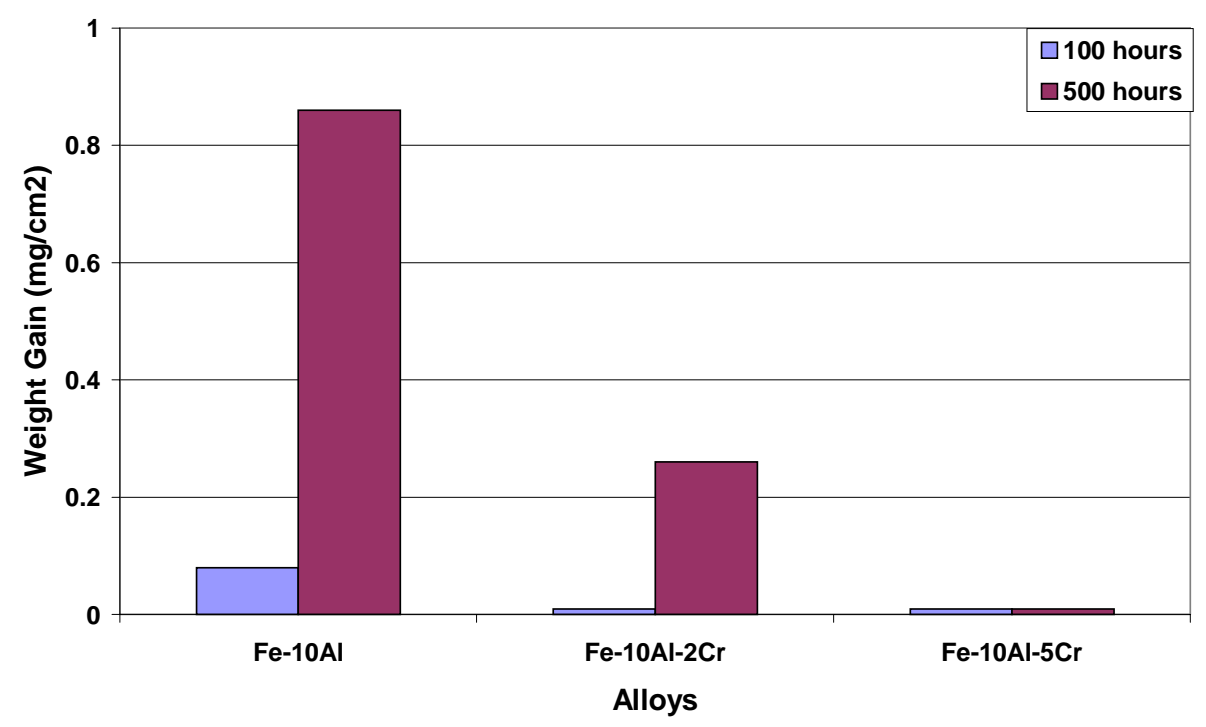

Figure 9 - Corrosion results for alloys exposed to the oxidizing environment at $500^{\circ} \mathrm{C}$. 


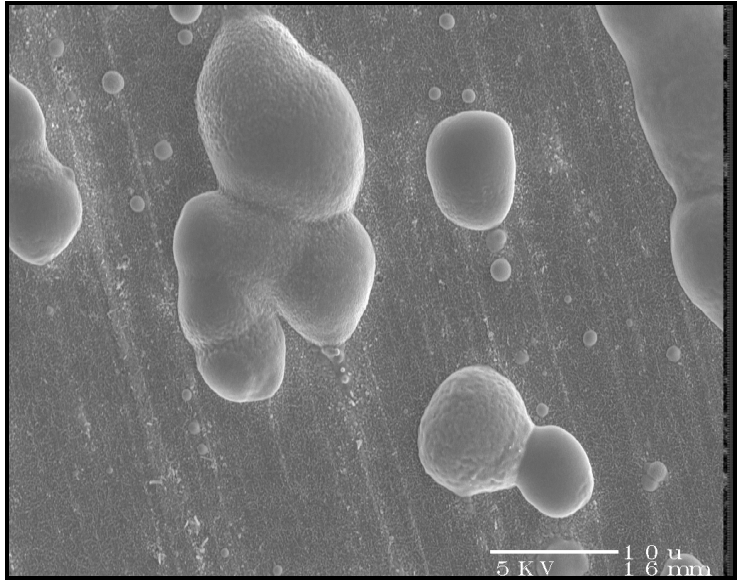

(a)

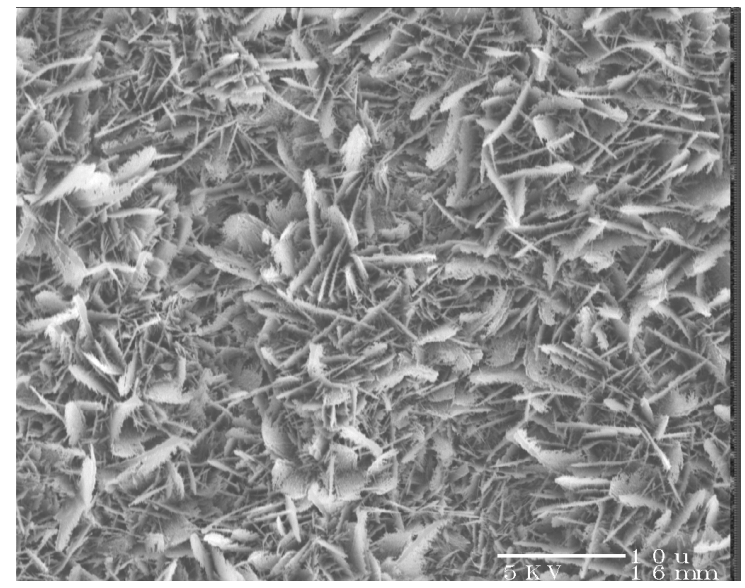

(b)

Figure 10 - Two types of corrosion products found on the Fe-10Al sample exposed to the oxidizing environment for 500 hours. The sphere-like nodules that formed on bare metal (a) and the plate-like scale that grew from the sphere-like nodules (b) were both identified using EDS as iron oxides.

\section{Mixed Oxidizing/Sulfidizing Environment}

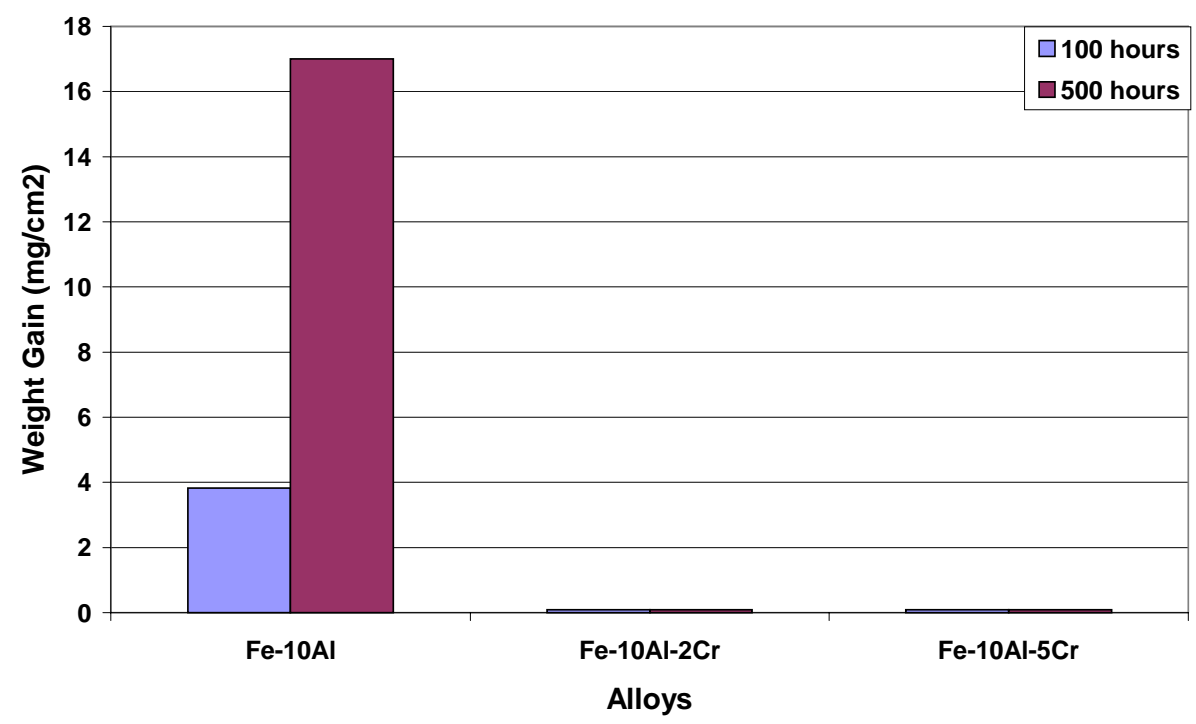

Figure 11 - Corrosion results for alloys exposed to the mixed oxidizing/sulfidizing environment at $500^{\circ} \mathrm{C}$. Note the change in the weight gain axis from Figure 9. 


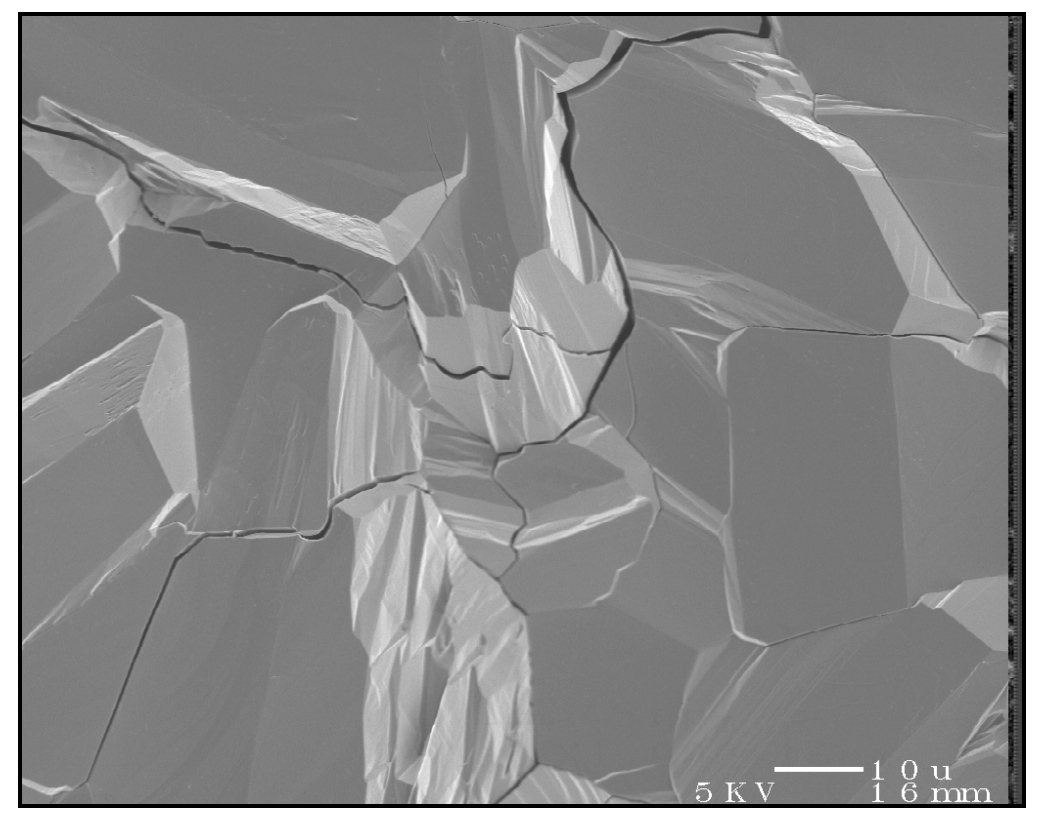

Figure 12 - Scale morphology of thick iron sulfide scale that formed on the Fe-10Al sample exposed to the mixed oxidizing/sulfidizing gas for 500 hours.

\subsection{FUTURE WORK}

Preliminary results showed that binary Fe-Al weld overlays can be deposited crack free below approximately $10 \mathrm{wt} \% \mathrm{Al}$, regardless of the welding parameters. It was also found that crack-free Fe-Al-Cr weld overlays can successfully be deposited using two separate filler metal wires. Preliminary corrosion testing showed that Fe-10Al was not corrosion resistant in the oxidizing and mixed oxidizing/sulfidizing environments for 500 hours of exposure, but that $\mathrm{Fe}-10 \mathrm{Al}-5 \mathrm{Cr}$ was completely protective in both environments up to 500 hours.

Future work will include depositing ternary Fe-Al-Cr weld overlays over a wide range of aluminum (5-15\%) and chromium (0-10\%) compositions. The welds will be examined for cracking and a compositional welding boundary will be established for ternary Fe-Al-Cr weld overlay coatings. TEM analysis will be performed on selected weld overlays that have compositions on either side of the crack/no crack compositional boundary. Observations will be made on the TEM to determine if the presence of the ordered intermetallic phase, $\mathrm{Fe}_{3} \mathrm{Al}$, influences the weld susceptibility to hydrogen 
cracking. Selected crack-free welds that have the highest alloying contents will be used for long-term corrosion testing. Cast alloys will be produced with equivalent alloy composition and coupons will be taken from the cast alloys for corrosion testing. Corrosion testing will be performed in the oxidizing and the mixed oxidizing/sulfidizing environments for exposure times up to 2000 hours. The results from this work should produce ternary $\mathrm{Fe}-\mathrm{Al}-\mathrm{Cr}$ weld overlay coating compositions that are immune to hydrogen cracking and are corrosion resistant for long exposure times.

\section{ACKNOWLEDGEMENTS}

This research was sponsored by the Fossil Energy Advanced Research and Technology Development (AR\&TD) Materials Program, US Department of Energy, under subcontract 19X-SU604V with UT Battelle Research Corporation. The authors would like to thank V.K. Sikka, B.A. Pint, and P.F. Tortorelli of Oak Ridge National Laboratory for the cast alloys used in the corrosion experiments and M. Rex, D. Ackland, and A.O. Benscoter for their aid in the welding setup and microscopy. 


\subsection{REFERENCES}

1. P.F. Tortorelli and J.H. DeVan, Compositional influences on the high-temperature corrosion resistance of iron aluminides. (1994). Process., Prop. Appl. Iron Aluminides. The Minerals, Metals \& Materials Society, Warrendale, PA, pp. 25770 .

2. K. N. Strafford and R. Manifold, Effects of aluminum alloying additions on the sulfidation behavior of iron. Oxid. Metals 5, pp. 85-112 (1972).

3. J. H. DeVan and P. F. Tortorelli, The Oxidation-Sulfidation Behavior of Iron Alloys Containing 16-40at\% Aluminum. Corros. Sci. 35, pp. 1065-1071 (1993).

4. S. W. Banovic, J. N. DuPont, and A. R. Marder, Corrosion resistance of weldable Fe-Al alloys in reducing environments. (1999). National Association of Corrosion Engineers. Corrosion 99. April 25, 1999.

5. S. W. Banovic, J. N. DuPont, and A. R. Marder, Growth of nodular corrosion products on $\mathrm{Fe}-\mathrm{Al}$ alloys in various high-temperature gaseous environments. Oxid. Metals 54, pp. 339-69 (2000).

6. C. G. McKamey, J. H. DeVan, P. F. Tortorelli, and V. K. Sikka, A review of recent developments in iron-aluminum (Fe3Al)-based alloys. J. Mater. Res. 6, pp. 1779-1805 (1991).

7. S. W. Banovic, J. N. DuPont, P. F. Tortorelli, and A. R. Marder, The role of aluminum on the weldability and sulfidation behavior of iron-aluminum cladding. Weld. Res. (Miami) 78, pp. 23S-30S (1999).

8. S. W. Banovic, J. N. DuPont, and A. R. Marder, Evaluation of Low Aluminum Fe-Al Alloys for Use as Weld Overlay Coatings in Reducing Environments. (1999) In Proceedings from Materials Solutions Conference '99 on Joining of Advanced and Specialty Materials, ASM International, Metals Park, OH. pp. 193-99.

9. J.R. Regina, J.N. DuPont, and A.R. Marder, Fe-Al Weld Overlay and High Velocity Oxy-Fuel Thermal Spray Coatings for Corrosion Protection of Waterwalls in Fossil Fired Plants with Low NOx Burners. ORNL Final Report \#ORNL/Sub/95-SU604/04. Under contract DE-AC05-00OR22725 (2001).

10. C.T. Liu, E.H. Lee, and C.G. McKamey, An Environmental Effect as the Major Cause for Room-Temperature Embrittlement in FeAl. Scripta Met. 23, pp. 87580 (1989).

11. C.T. Liu, C.G. McKamey, and E.H. Lee, Environmental Effects on RoomTemperature Ductility and Fracture in Fe ${ }_{3} \mathrm{Al}$. Scripta Met. 24, pp. 385-89 (1990). 
12. C.T. Liu, C.L. Fu, E.P. George, and G.S. Painter, Environmental Embrittlement in FeAl Aluminides. ISIJ International 31(10), pp. 1192-1200 (1991).

13. V.K. Sikka, S. Viswanathan, and S. Vyas, Acceptable Aluminum Additions for Minimal Environmental Effect in Iron-Aluminum Alloys. pp. 971-76 in HighTemperature Ordered Intermetallic Alloys V, ed. I. Baker, R. Darolia, J.D. Whittenberger, and M.H. Yoo, Materials Research Society (1993).

14. M.P. Speidel, Hydrogen Embrittlement of Aluminum Alloys?, pp. 329-51 in Hydrogen Damage, ed. C.D. Beachem, ASM Publication (1974).

15. S. Vyas, S. Viswanathan, and V.K. Sikka, Effect of Aluminum Content on Environmental Embrittlement in Binary Iron-Aluminum Alloys. Scripta Met. 27, pp. 185-90 (1992).

16. C.G. McKamey, J.A. Horton, and C.T. Liu, Effect of Chromium on Room Temperature Ductility and Fracture Mode in $\mathrm{Fe}_{3} \mathrm{Al}$. Scripta Met. 22, pp. 1679-81 (1988).

17. C.G. McKamey and C.T. Liu, Chromium Addition and Environmental Embrittlement in $\mathrm{Fe}_{3} \mathrm{Al}$. Scripta Met. 24, pp. 2119-22 (1990). 